\title{
Sexual health and the practice nurse: a survey of reported practice and attitudes
}

\author{
Tim Stokes, MPH, MRCGP, DFFP \\ Clinical Lecturer in General Practice, Department of General Practice and Primary Health Care, University of Leicester, \\ Leicester General Hospital, Gwendolen Road, Leicester LE5 4PW, UK \\ General Practitioner, East Leicester Medical Practice, Leicester, UK
}

Judith Mears, RGN

Research Nurse/Practice Nurse

East Leicester Medical Practice, Uppingham Road Health Centre, 131 Uppingham Road, Leicester, LE5 4BP, UK

(Accepted December $\left.13^{\text {th }}, 1999\right)$

\begin{abstract}
Summary
Background. Practice nurses have an important role in the provision of sexual health services in general practice.

Aim. This study set out to determine practice nurses' reported practice and training in sexual health, attitudes towards sexual health, barriers to discussing sexual health with patients, and training needs.

Method. A confidential self-administered postal questionnaire survey was sent to all 298 practice nurses in one English health district (Leicestershire).

Results. Completed questionnaires were returned by 234 practice nurses (response rate $79 \%$ ). Most nurses routinely offered well-person checks (90\%), cervical smears (89\%), travel clinics (83\%), saw women with genito-urinary symptoms (77\%) and offered family planning advice (54\%). Only a minority of nurses (13\%) offered specific teenage health clinics. Sexual health issues were always discussed in a majority of consultations when giving family planning advice (65\%) and in women with genito-urinary symptoms (58\%). Most practice nurses (62\%) had undertaken at least one course dealing with sexual health issues in the last 5 years. Uptake of training was, however, significantly lower in certain groups of nurses. An analysis of the attitude statements suggested that nurses were more comfortable discussing sexual health issues with female patients and teenagers than with male patients and those of different sexual orientations. Nurses who had received training reported more positive attitudes towards discussing sexual health issues with patients.

Conclusion. Practice nurses offer a wide range of services in which the need to be able to take a sexual history and offer appropriate advice is important. There is scope to improve the provision of sexual health services by nurses in general practice, particularly in relation to services for teenagers.
\end{abstract}

Key words

practice nursing; sexual health

\section{Key message points}

- Practice nurses offer a wide range of services in which the ability to take a sexual history and offer appropriate advice is important.

- Nurses are more comfortable discussing sexual health issues with female patients and teenagers than with men and those of different sexual orientations.

- Nurses who had received training reported more positive attitudes towards discussing sexual health issues with patients.

There is scope to improve the provision of sexual health services by nurses in general practice.

\section{Introduction}

Sexual health has been defined as 'the enjoyment of the sexual activity of one's choice without suffering physical or mental harm'. ${ }^{1}$ Unfortunately sexual activity can have unintended outcomes such as pregnancy, sexually transmitted infections (STIs) and infertility. General practice is an important provider of sexual health services in the UK and both general practitioners (GPs) and practice nurses regularly deal with sexual health issues such as contraception, STIs and psycho-sexual concerns. ${ }^{1}$ There has been recent interest in the expansion of services to include sexual health advice to teenagers ${ }^{2}$ and screening for genital chlamydial infection. ${ }^{3}$

Practice nurses have a key role in the provision of sexual health services in general practice. They may offer family planning advice, do cervical smears and be the first point of contact of women with genito-urinary symptoms. They may also run travel, teenage and well-person clinics. ${ }^{2,4-6}$ In these settings the ability to take a sexual history and offer appropriate advice is important. Practice nurses may be better placed to discuss sexual health with patients than GPs, given their established role in health promotion and longer consultation times. ${ }^{7,8}$ It is, however, likely that barriers exist to dealing with sexual health issues in practice nurse consultations. Such barriers include lack of time, lack of knowledge, embarrassment and poor communication skills. ${ }^{7}$

Little is known about how practice nurses view sexual health issues. A qualitative study of sexual health and family planning services in general practice commissioned by the Family Planning Association was carried out in 1992..$^{9}$ This involved face-to-face interviews with 20 practice nurses drawn from 60 general practices in England and Wales. The authors concluded that there was scope for practice nurses to become more involved in sexual health issues; $<50 \%$ of practice nurses surveyed had any family planning qualifications. Practice nurses wanted more training in family planning, sexuality, abortion and psycho-sexual counselling. While such research is useful, there remains a need to quantify attitudes towards sexual health among practice nurses and to determine whether more positive attitudes are associated with training. It is also important to describe current clinical practice. We therefore undertook a study to describe reported practice, training received, attitudes towards sexual health issues, barriers to discussing sexual health with patients and perceived training needs of practice nurses in one English health district.

\section{Methods}

Questionnaire development and sample

A district-wide sample of practice nurses was used as the survey results were to be used to inform local provision of sexual health training courses. The questionnaire was piloted in the Leicester University Department of General Practice and Primary Health Care. The revised pilot 
questionnaire was sent to 10 practice nurses identified from the Leicestershire Health Authority/Primary Care Audit Group database. All pilot questionnaires were returned. The results led to a small number of minor alterations to the wording of the questionnaire. These pilot questionnaires are included in the main analysis. All 298 practice nurses working in Leicestershire/Rutland (except those practice nurses in the pilot study and JM) were sent the final questionnaire in March 1998. Non-responders were sent one follow-up questionnaire 3 weeks later.

The self-administered structured questionnaire had 29 questions. Most required a closed response. Information was obtained on the following areas: demographic characteristics; sexual health training received; services offered; settings in which sexual health is discussed; attitudes towards discussing sexual health issues in different settings; perceived barriers to discussing sexual health issues with patients ${ }^{4}$ and the perceived need for further training. Practice nurses' attitudes towards raising sexual health issues within the consultation were explored by 12 attitude statements using a five-point Likert-type scale. ${ }^{10}$ Respondents chose one response from strongly agree (scoring one) to strongly disagree (scoring five). The statements were developed from existing research on sexual history taking in general practice. ${ }^{4}$ They covered: taking a sexual health history; discussing sexual health issues with female patients, male patients, teenagers and patients of a different sexual orientation, and whether knowledge about HIV/AIDS and other STIs was adequate. Acquiescence bias (the tendency to give positive responses to a question) was minimised by ensuring that the statements were both positively and negatively worded. ${ }^{10}$

\section{Data collection and analysis}

The data was entered onto Epi Info 6 database and statistical package. All the questionnaires were entered twice and validated. Statistics were calculated using SPSS for Windows. The chi square test was used to compare details of those who reported training in sexual health issues with those who reported no training. The mean attitude scores of those who reported training were compared with the scores of those who reported receiving no training, using the Mann Whitney- $U$ test.

\section{Results}

Completed questionnaires were received from 234 of the 298 practice nurses $(79 \%)$. There was no difference in the response rate between practice nurses who worked in a general practice in the City of Leicester (113/144, 79\%) compared with those practising in Leicestershire/Rutland $(121 / 154,79 \%)$. Nearly one third of responders $(32 \%)$ wanted a copy of the survey results.

\section{Practice nurse characteristics}

All 234 respondents were women. Their age ranges were: under 35: 10\%, 35 to 50: $62 \%$ and over 50: $28 \%$. Their length of time as a practice nurse was: under 5 years: $23 \%$, 5 to 10 years: $53 \%$ and over 10 years: $24 \%$. Their hours worked per week were: less than 10 hours: $5 \%, 10$ to 24 hours: $52 \%$ and over 24 hours: $44 \%$. Approximately equal numbers of nurses worked in both locations (City of Leicester 48\%, Leicestershire/Rutland 52\%).

\section{Services offered}

The practice nurses were asked whether or not they routinely offered a range of services (Table 1). The most frequently offered services were well-person checks $(90 \%)$, cervical smears $(89 \%)$ and travel clinic (83\%). A majority of nurses also routinely saw women with genito-urinary symptoms (77\%) and offered family planning advice (54\%). Only a minority of practice nurses $(13 \%)$ offered specific teenage health clinics. For those services that they routinely offered they were asked to report whether they discussed sexual health issues with patients (Table 1). Sexual health issues were defined as including 'giving contraceptive advice, discussing 'safe sex' and exploring concerns about sexually transmitted diseases'. Sexual health issues were always discussed in a majority of consultations in a teenage clinic $(73 \%)$, when giving family planning advice $(65 \%)$ and in women with genito-urinary symptoms $(58 \%)$.

\section{Training undertaken in sexual health}

A majority of practice nurses $(144 / 232,62 \%)$ reported having undertaken at least one course dealing with sexual health issues in the last 5 years. Younger nurses were significantly more likely to have reported training $(69 \%$ of nurses aged 50 or under compared with $43 \%$ of those aged over $\left.50, \chi^{2}=13.83,1 \mathrm{df}, \mathrm{p}<0.001\right)$ as were nurses working more hours $(71 \%$ of nurses working 25 hours or more compared with $55 \%$ of those working less than 25 hours, $\chi^{2}=5.68,1 \mathrm{df}, \mathrm{p}=0.02$ ).

Of the 144 respondents who reported undertaking training in the last 5 years, $82(57 \%)$ had undertaken the Marie Curie Course on breast and cervical screening, 60 (42\%) had undertaken the English National Board (ENB) family planning course and $62(43 \%)$ had attended any other course dealing with sexual health issues. The most frequent 'other courses' reported by the practice nurses were cervical cytology course (14), non-ENB family planning course (10) and local condom distribution project (8). Of those nurses whom routinely offered cervical smears (Table 1), only a minority held the Marie Curie course on breast and cervical screening $(82 / 204,47 \%)$. Of those nurses who routinely offered family planning advice

Table 1 Frequency of services offered by practice nurses and how often sexual health issues are discussed with patients in each of these settings.

\begin{tabular}{|c|c|c|c|c|c|c|c|c|c|c|}
\hline \multirow{2}{*}{$\begin{array}{l}\text { Service offered }^{\mathrm{a}} \\
\text { Well-person checks }\end{array}$} & \multirow{2}{*}{$\frac{n^{b}}{230}$} & \multicolumn{2}{|c|}{$\begin{array}{l}\text { Number }(\%) \text { of } \\
\text { practice nurses who } \\
\text { routinely offered service }\end{array}$} & \multirow{2}{*}{$\frac{\mathrm{n}^{\mathrm{c}}}{197}$} & \multicolumn{6}{|c|}{ How often sexual health issues discussed with patients (\%) } \\
\hline & & 206 & $(90)$ & & 36 & $(18)$ & 155 & (79) & 6 & (3) \\
\hline Cervical smears & 230 & 204 & $(89)$ & 199 & 78 & (39) & 121 & (61) & 0 & (0) \\
\hline Travel clinic & 229 & 189 & $(83)$ & 179 & 35 & (20) & 136 & (76) & 8 & (4) \\
\hline See women with genito-urinary symptoms ${ }^{\mathrm{d}}$ & 229 & 176 & (77) & 164 & 95 & $(58)$ & 68 & (41) & 1 & (1) \\
\hline Family planning advice & 225 & 121 & (54) & 117 & 76 & $(65)$ & 41 & (35) & 0 & $(0)$ \\
\hline Teenage clinic & 227 & 29 & (13) & 26 & 19 & (73) & 6 & (23) & 1 & (4) \\
\hline
\end{tabular}

aArranged in descending order of service offered.

${ }^{b}$ Number of practice nurses responding to question asking whether they routinely offered service.

${ }^{\mathrm{c}}$ Number of practice nurses who routinely offered service responding to question asking how often they discussed sexual health issues with patient.

de.g. 'women with a vaginal discharge'. 
Table 2 Practice nurses' responses to statements measuring attitudes towards raising sexual health issues with patients

\begin{tabular}{|c|c|c|c|c|}
\hline \multirow[b]{2}{*}{ Statement $^{\mathrm{a}}$} & \multirow[b]{2}{*}{$\mathrm{n}^{\mathrm{b}}$} & \multicolumn{3}{|c|}{ Number $(\%)$ of respondents who } \\
\hline & & Agreed $^{\mathrm{c}}$ & nor disagreed & Disagreed $^{\mathrm{d}}$ \\
\hline I feel comfortable discussing sexual health issues with female patients & 228 & $203(89)$ & $20(9)$ & $5(2)$ \\
\hline I feel comfortable discussing sexual health issues with teenagers & 225 & $174(77)$ & $43(15)$ & $17(8)$ \\
\hline I am happy with my ability to take a sexual history from patients & 226 & $140(62)$ & $42(19)$ & $44(20)$ \\
\hline I feel comfortable discussing sexual health issues with male patients & 225 & $123(55)$ & $54(24)$ & $48(21)$ \\
\hline I feel comfortable discussing sexual health issues with patients of a different sexual orientation & 226 & $101(45)$ & $70(31)$ & $55(24)$ \\
\hline I find that discussing sexual health issues with male patients makes me feel uncomfortable & 225 & $59(26)$ & $55(24)$ & $111(49)$ \\
\hline I do not feel confident about taking a sexual history from patients & 225 & $57(25)$ & $33(15)$ & $135(60)$ \\
\hline I find that discussing sexual health issues with patients of a different sexual orientation makes & & & & \\
\hline me feel uncomfortable & 226 & $41(18)$ & $73(32)$ & $112(50)$ \\
\hline I find that discussing sexual health issues with teenagers makes me feel uncomfortable & 223 & $23(10)$ & $34(15)$ & $166(74)$ \\
\hline I find that discussing sexual health issues with female patients makes me feel uncomfortable & 225 & $11(5)$ & $24(11)$ & $190(84)$ \\
\hline I feel my knowledge about HIV/AIDS is adequate & 226 & $110(49)$ & $62(27)$ & $54(24)$ \\
\hline $\begin{array}{l}\text { I feel my knowledge about other sexually transmitted diseases (e.g. genital warts, Chlamydia) } \\
\text { is adequate }\end{array}$ & 230 & $113(49)$ & $56(24)$ & $61(27)$ \\
\hline
\end{tabular}

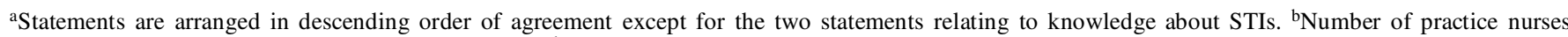
responding. ${ }^{\mathrm{c}}$ Responses: strongly agree, tend to agree. ${ }^{\mathrm{d}}$ Responses: strongly disagree or tend to disagree.

(Table 1), only a minority held an ENB family planning course $(55 / 121,46 \%)$.

\section{Attitudes towards discussing sexual health issues}

Table 2 presents the responses of the practice nurses to the attitude statements. Practice nurses appear to be more comfortable discussing sexual health issues with female patients $(89 \%)$ and teenagers $(77 \%)$ than with male patients $(54 \%)$ and those of different sexual orientations (45\%).

Table 3 presents an analysis of attitude statement responses according to training status. A conservative Bonferroni correction (multiplying each $\mathrm{p}$ value by 12 , the number of hypothesis tests performed) was applied to adjust for multiple hypothesis testing. ${ }^{11}$ Practice nurses who reported having received training in sexual health in the last 5 years had significantly lower mean scores on statements assessing positive attitudes towards discussing sexual health issues with patients when compared with practice nurses who reported no training. Practice nurses who reported having received training in sexual health in the last 5 years also had significantly higher mean scores on statements assessing negative attitudes towards discussing sexual health with patients (with the exception of male patients) when compared with practice nurses who reported no training. This suggests that practice nurses who report training in sexual health hold more positive attitudes towards discussing sexual health issues with patients.

Barriers to discussing sexual health and training needs The practice nurses were asked to respond to a series of statements describing problems they may have had while taking a sexual history from a patient (Table 4). Most practice nurses saw lack of time (64\%), lack of training (61\%) and concern about not being able to cope with the issues raised $(53 \%)$ as barriers to discussing sexual health with patients. The majority of practice nurses $(217 / 225,93 \%)$ stated that they would attend a local training course in sexual health.

\section{Discussion}

This survey provides information about knowledge, reported practice and attitudes towards sexual health issues in a district-wide sample of practice nurses. The results presented are of self-reported attitudes and behaviour and the practice nurses who responded are probably those most interested in sexual health issues. It is therefore likely that the results represent 'best practice' by practice nurses.

Table 3 Scores of attitude statements by practice nurses who reported having undertaken at least one course dealing with sexual health issues in the last 5 years and those who had not attended such courses

\begin{tabular}{|c|c|c|c|c|c|}
\hline \multirow[b]{2}{*}{ Statement } & \multicolumn{5}{|c|}{ Mean score of practice nurses ${ }^{b}$} \\
\hline & $\mathrm{n}^{\mathrm{a}}$ & training & no training & $\mathrm{Z}^{\mathrm{c}}$ & P value \\
\hline I feel comfortable discussing sexual health issues with female patients & $141 / 85$ & 1.6 & 2.0 & 4.6 & $<0.001 *$ \\
\hline I feel comfortable discussing sexual health issues with teenagers & $140 / 83$ & 1.9 & 2.3 & 4.4 & $<0.001 *$ \\
\hline I am happy with my ability to take a sexual history from patients & $140 / 84$ & 2.1 & 2.7 & 4.6 & $<0.001 *$ \\
\hline I feel comfortable discussing sexual health issues with male patients & $138 / 85$ & 2.6 & 2.5 & 0.6 & 0.583 \\
\hline $\begin{array}{l}\text { I feel comfortable discussing sexual health issues with patients of a different } \\
\text { sexual orientation }\end{array}$ & $140 / 84$ & 2.5 & 3.0 & 4.0 & $<0.001 *$ \\
\hline I find that discussing sexual health issues with male patients makes me & & & & & \\
\hline feel uncomfortable & $138 / 85$ & 3.5 & 3.2 & 1.9 & 0.057 \\
\hline I do not feel confident about taking a sexual history from patients & $139 / 84$ & 3.8 & 3.3 & 3.5 & $<0.001 *$ \\
\hline $\begin{array}{l}\text { I find that discussing sexual health issues with patients of a different sexual } \\
\text { orientation makes me feel uncomfortable }\end{array}$ & $140 / 84$ & 3.6 & 3.3 & 2.4 & 0.016 \\
\hline $\begin{array}{l}\text { I find that discussing sexual health issues with teenagers makes me } \\
\text { feel uncomfortable }\end{array}$ & $138 / 83$ & 4.1 & 3.6 & 4.6 & $<0.001 *$ \\
\hline $\begin{array}{l}\text { I find that discussing sexual health issues with female patients makes me } \\
\text { feel uncomfortable }\end{array}$ & $139 / 84$ & 4.4 & 3.9 & 4.8 & $<0.001 *$ \\
\hline I feel my knowledge about HIV/AIDS is adequate & $140 / 84$ & 2.5 & 3.0 & 3.4 & $0.001 *$ \\
\hline $\begin{array}{l}\text { I feel my knowledge about other sexually transmitted diseases } \\
\text { (e.g. genital warts, Chlamydia) is adequate }\end{array}$ & $140 / 88$ & 2.5 & 3.1 & 5.0 & $<0.001 *$ \\
\hline
\end{tabular}

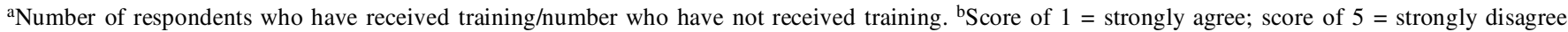
${ }^{\mathrm{c}}$ Comparison of scores between groups, Mann Whitney $U$-test. *Results significant at $5 \%$ level after applying Bonferroni correction. 
Table 4 Number and percentage of practice nurses who agreed that the following series of statements described possible barriers to taking a sexual history from a patient

\begin{tabular}{|c|c|c|}
\hline Statement & $\mathrm{n}^{\mathrm{a}}$ & $\begin{array}{l}\text { Number (\%) } \\
\text { of responders } \\
\text { who agreed with }\end{array}$ \\
\hline
\end{tabular}

Lack of time prevents me from discussing sexual health issues as often as I'd like to

Lack of training in communication skills prevents me from discussing sexual health issues as often as I'd like to

$134(61)$

all the issues that may be raised when

discussing sexual health issues

Interruptions to my clinic prevent me from

discussing sexual health issues as often as

I'd like to

I find sexual health issues embarrassing
213
${ }^{a}$ Number of responders

The response rate $(79 \%)$ is satisfactory for a postal survey of practice nurses. Although national data on practice nurses are not routinely available, the age and working hours of the respondents are similar to those reported in an earlier survey of practice nurses in the South West Thames Regional Health Authority ${ }^{5}$ and the 1992 national census of practice nurses. ${ }^{6}$ Also Leicestershire Health is one of the largest Health Authorities in England and Wales (population 900000 ) with a study population of over 150 general practices in a variety of inner city, urban and rural settings. The results presented here may thus be generalisable to practice nurses throughout England and Wales.

The practice nurses offered a wide range of services in which sexual health issues were discussed with patients. It is interesting that, as with other studies, ${ }^{6}$ only a minority of practice nurses offered special teenage clinics. A recent national study reported substantial sexual ill health (unintended pregnancies, STIs) among teenagers in England and Wales. ${ }^{12}$ These findings emphasise the need for more to be done in primary care to address teenage sexual health. ${ }^{1,2}$ However, the fact that practice nurses themselves felt comfortable discussing sexual health issues with teenagers, even if they did not offer special clinics, is consistent with other published research, and supports arguments that practice nurses should become more involved in the delivery of such services in general practice.

It is encouraging that a majority of practice nurses $(62 \%)$ reported having undertaken at least one course dealing with sexual health issues in the last 5 years. It is, however, a matter of concern that older nurses and those who work fewer hours are less likely to have attended such courses. These findings are consistent with those of an earlier study which showed that practice nurses who were older and who worked fewer hours were less likely to want to extend their role or attend further training courses. ${ }^{5}$

Practice nurses appear to be more comfortable discussing sexual health issues with female patients than with male patients and those of a different sexual orientation to themselves. Although caution should be exhibited in interpreting the results of single item responses, one would expect health care professionals to feel more comfortable discussing sexual health issues with those of the same sex and those of the same sexual orientation. ${ }^{4}$

An analysis of the attitude scores suggests that practice nurses who report training in sexual health hold more positive attitudes towards discussing sexual health issues with patients. These results must, however, be interpreted with care. It is possible that the observed differences may simply reflect variation in the way in which practice nurses respond to single items in questionnaires. Also, even if one believes that the differences in attitudes represent a difference in actual behaviour, one cannot conclude that training alone is associated with an increased discussion of sexual health issues in the consultation. It has already been shown that nurses who have received training are more likely to be younger and to work longer hours. It is likely that these factors will confound any effect seen with training. Although this study design can only suggest that training in sexual health is associated with more positive attitudes, there is some evidence to support this hypothesis: a 'before and after' evaluation of a HIV/AIDS workshop for primary care staff showed a significant improvement in attitudes towards the prevention and management of HIV in general practice. ${ }^{13}$

Lack of time, lack of training and concern about not being able to cope with the issues raised appear to be important barriers to discussing sexual health in practice nurse consultations. The survey findings appear to confirm earlier qualitative research exploring these issues. ${ }^{4,7}$ As in the 1992 study, ${ }^{9}$ practice nurses in 1998 still wish to attend locally provided training courses on sexual health. Such courses should involve all key providers in sexual health services at district level.

In conclusion, practice nurses offer a wide range of services in which the need to be able to take a sexual history and offer appropriate advice is important. Although most nurses appear to have received at least some training, there is a need to ensure that they have access to appropriate professional courses. It should be noted that only a minority of nurses routinely offering family planning advice have undertaken an appropriate ENB course within the last 5 years. If such training and organisational needs can be addressed, then there is scope to improve the provision of sexual health services by nurses in general practice. One priority area should be an expansion in the provision of sexual health services for teenagers by practice nurses.

\section{Acknowledgements}

We should like to thank all the Leicestershire practice nurses who filled in the questionnaire and the clerical staff of the East Leicester Medical Practice for their secretarial assistance. We should also like to thank Tim Coleman and Francine Cheater of the Department of General Practice and Primary Health Care, University of Leicester for their advice. The Eas Leicester Medical Practice is a designated research general practice funded by Trent Focus for research and development in primary care.

\section{Statements on funding and competing interests}

Funding. None

Competing interests. None.

\footnotetext{
References

Carter Y, Moss C, Weyman A (eds). RCGP Handbook of Sexual Health in Primary Care. London: Royal College of General Practitioners, 1998.

Gregg R, Freeth D, Blackie C. Teenage health and the practice nurse: choice and opportunity for both? Br J Gen Pract 1998; 48: 909-910.

Stokes T, Santer M, Mears J. Screening for genital chlamydial infection: the agenda for general practice. Br J Gen Pract 1999; 49: 427-428.

Jewitt C. Sexual History Taking in General Practice. London: The HIV Project, 1995. Ross FM, Bower PJ, Sibbald BS. Practice nurses: characteristics, workload and training needs.

Br J Gen Pract 1994; 44: 15-18.
6 Atkin K, Hirst M, Lunt N, Parker G. The role and self-perceived training needs of nurses employed in general practice: observations from a national census of practice nurses in England and Wales. Journal of Advanced Nursing 1994; 20: 46-52.

Peate I. Taking a sexual health history: the role of the practice nurse. British Journal of Nursing 1997; 6: 978-983.

Jefreys LA, Clark AL, Koperski M. Practice nurses' workload and consultation patterns. $\mathrm{Br}$ Gen Pract 1995 ; 4: 415-418.

Repily Planning Association. Sexual health and family planning services in general practice. Report of a qualitative research survey in England and Wales. London: FPA, 1993

Streiner DL, Norman GR. Health Measurement Scales A Practical Guide to their Developmen and Use. Oxford: OUP, 1989

12 Nicoll A, Catchpole M, Cliffe S, Hughes G Sesearch. London: Chapman \& Hall, 1991. in England and Wales: analysis of national data. BMJ 1999; 318: 1321-322.

Sibbald B, Freeling P, Coles H, Wilkins J. HIV/AIDS workshop for primary health care staff. Medical Education 1991; 25: 243-250.
} 